\title{
Barriers Related to Al Implementation in Supply Chain Management
}

Monika Shrivastav, Walmart, USA*

\begin{abstract}
The primary objective of this paper is to offer a structured and comprehensive list of the barriers associated with implementation of artificial intelligence (AI) solutions in supply chain management (SCM). While the broader field of AI has made rapid advances in a relatively short period of time, there are significant barriers that still need to be addressed to harness the true potential of AI. SCM's dependency on multi-actor collaboration, disparate data sources, unwillingness of actors to embrace AI, change management issues, and lack of AI governance framework poses significant barriers for successful implementation of AI. Drawn from extensive literature review as well as real-world experience, this paper systematically explores and compiles a robust list of barriers of AI implementation in supply chain functions by categorizing them and elaborating their impact at inter- and intra-organizational SCM. Lastly, the paper offers recommendations for practitioners, policymakers, researchers, and governments on how they can work together for AI to be successful.
\end{abstract}

\section{KEYWORDS}

Adoption, Artificial Intelligence, Challenges, Change Management, Inter-Organizational Barrier, Leadership, Organizational Barrier, SCM, Supply Chain Management

\section{INTRODUCTION}

The World Economic Forum has described the modern day as an era of Fourth Industrial Revolution where everything is connected, and that we have access to unprecedented computing power and storage capacities (World Economic Forum, 2016). This has led to explosion of data, which in turn has enabled an exponential leap for technologies like Artificial Intelligence (AI), Internet of Things (IoT), robotics, and quantum computing (The Royal Society, 2017; Bernhardt, 2019). Moreover, the pace at which these technologies are advancing has been the fastest when compared with earlier industrial revolutions. This rapid pace of advancement has created asymmetry in not only understanding the true potential of the technologies, but also how to implement them. One of these technologies - AI has been touted for achieving super-human intelligence, enabling products that have seamlessly become part of our daily routines, and making businesses more productive and efficient.

One of the key sectors where AI has tremendous potential is Supply Chain Management (SCM) which is about strategic coordination both within the company and across various businesses in the supply chain with eventual objective of productivity gains for each player thereby delivering value to the end consumer (Mentzer et al., 2001; Hugos, 2018; Christopher, 2016). It is about flow of goods, services, or information from raw materials all the way to the customer. Historically, SCM 
has been about building strategies and process related to production of goods, planning, inventory management and availability, transportation and logistics and end delivery to customer. The present day SCM builds on top of this foundation by aiming to be faster, connected, collaborative and intelligent thereby being more proactive in handling uncertainty and serve the modern-day consumer (Nasiri et al., 2020; Agarwal \& Narain, 2018).

As the Fourth Industrial Revolution is re-shaping every aspect of how we operate, it is also having profound effect on the way customers are making their choices and decisions. We are observing significant changes in consumer behavior: new shopping channels, faster delivery expectations, omnichannel presence, broad assortment, etc. In this fast-changing dynamic landscape, developing a trusted relationship with our customers is paramount to capturing and maintaining the market share. This stochastic nature of consumer demand implies higher risk, complexities, and uncertainty for almost every actor in the supply chain. This is where the promise of AI holds - its ability to create value and provide competitive edge in uncertain environment. This is also why we are seeing increasing adoption of AI in various supply chain areas like supplier selection, demand forecasting, smart warehousing and strategy and operations planning etc. (Dash et al., 2019; Helo \& Hao, 2021; Min, 2010; Singh, 2003; Toorajipour et al., 2021). AI is enabling businesses to make more intelligent decisions in an agile manner, and to be more proactive (vs reactive). Pairing AI with other advanced technologies like IoT, Blockchain etc., allows businesses to fully paint the picture of their global logistics network, thereby enabling better transparency in most aspects of its supply chain and interdependencies (AlTurjman, 2019; Evtodieva et al., 2020; Singh et al., 2020). This results in productivity gains, lower costs and most importantly meeting the customer demand whenever and wherever they want a product.

While AI has been gaining adoption across various functions in the supply chain management, there have been significant challenges and barriers that organizations are facings while implementing AI. Infact, a global survey conducted by McKinsey (Chui \& Malhotra, 2018) concluded that most industries have figured out business functions (e.g., marketing and sales, risk detection, product etc.) within their organizations where AI has most potential and have successfully implemented it thereby reaping benefits.

However, the same survey and many others (Cubric, 2020; Dwivedi et al., 2019) concluded that SCM is still a laggard when it comes to AI adoption. The purpose of this paper is to offer an extensive and robust review of barriers that are affecting this adoption in SCM and offer possible remedies to overcome these barriers.

The rest of the paper is organized as follows: It starts with fundamentals of AI and highlights general challenges associated with implementing AI across any industry. Next, it discusses SCM, its various functions, and highlight few use-case where AI can be applied. Thirdly, it will take deep dive into barriers of implementing AI across inter- and intra- organizational SCM. Finally, it provides some recommendation for AI enablers to overcome the barriers.

\section{Artificial Intelligence: An Overview}

Artificial intelligence is a multi-disciplinary field of science that aims to build "intelligent" systems. Intelligence here is a broad term that usually refers to building systems that can act like humans or think like humans, or in some cases exceed human judgement (Russell \& Norvig, 2002; Bringsjord et al., 2017). Another way to understand AI is to think in terms of various tasks that a system needs to carry out to achieve intelligence. These tasks can be bucketed into four main categories: Learn, Perceive, Decide and Act (Moore, 2018). Figure 1 shows the schematic of this framework along with associated sub-fields within each task.

Machine Learning is a sub-field of AI that deals with learning from large amounts of data (Jordan \& Mitchell, 2015). Computer Vision is a perception field that aims to see (perceive) the world by using specialized hardware (e.g., camera) and aims to mimic the role of human eyes (Szegedy et al., 2016). Optimization and simulation can be thought of as sub-field of AI which aim to explore various alternatives to come up with most optimal solution given what we have learned and perceived about 


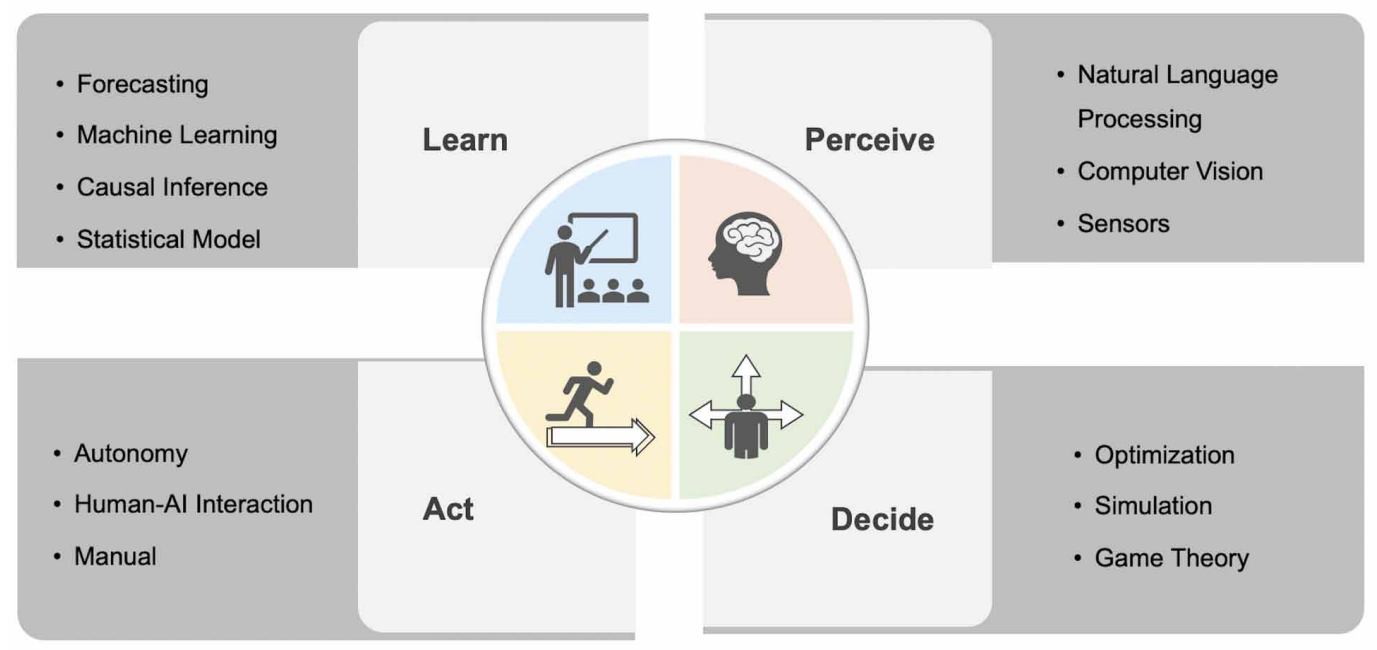

the external world and its constraints (Boyd et al., 2004). This specific branch of AI has classically been deployed across various areas of SCM (Bertsimas \& Thiele, 2004; Geunes \& Pardalos, 2003). Autonomy and Human-AI interaction are sub-fields within AI that aim to build approaches that help systems act on the decisions either fully or partially given what is most optimal and considering ethical, fairness and safety considerations (Amershi et al., 2019)

In industry, the term AI is synonymously used to refer a class of analytics/tools/systems that are built to either aid humans or to automate a certain task at hand. Both the academic literature and industry is filled with terminologies like analytics, predictive/reactive AI, functional AI etc., all referring to a specific use case on how a set of scientific algorithms are helping to either automate, aid, act or think like humans (Mehrotra, 2021; Michard \& Teboul, 2019; Stefanovic, 2014). One of the underlying sub-fields of AI that has shown explosive growth and widespread adoption in industry (including SCM) in last few years is Machine Learning. As explained above, Machine Learning is branch of AI that aims to build systems that directly learn from data, examples, or experience (Goodfellow et al., 2016; The Royal Society, 2017). Rather than using pre-programmed rules, a machine learning system can continuously learn from the data and keep getting better at performing certain specific tasks. This continuous learning from ever increasing data means that machine learning has ability to exceed human performance in one or many areas. Infact, it has already outperformed humans in image and voice recognition systems as well as personalized search recommendations (Krizhevsky et al., 2012; Rawat \& Wang, 2017).

There is yet another view of Artificial Intelligence where the objective of achieving intelligence is not to think or act like humans, but rather to think or act rationally (Russell \& Norvig, 2002). This in part to overcome the bias of irrationality in human beings like in stock market trading etc. When any AI system is trained to perform on a certain specific task, it is termed as "Narrow or Weak AI", while when a system is built with possibility to operate across plethora of tasks and under any environment, it is termed as "Strong AI" (Goertzel, 2017). The later has potential to achieve or even outperform human intelligence and hence it is sometimes also referred to as Artificial General Intelligence (AGI) or Artificial Super Intelligence (ASI).

Most systems that we have built today across various industries and have made progress academically are in realm of Weak AI (Gasser \& Almeida, 2017), with special emphasis on usage of Machine Learning relating to supervised learning (classification, regression), semi-supervised learning, unsupervised learning (clustering), and reinforcement learning. Strong AI, on other hand, is 
still a theoretical construct with no real-world examples in use today. However, when science fiction or media talks about AI, they usually portray or refer to Weak AI system as Strong AI system creating this perception that we are on verge of achieving AGI. In this paper, the term Artificial Intelligence or AI has been used to refer a weak AI system as strong AI is out of scope of this paper.

The disparity or lack of understanding of capabilities of different types of AI among business leaders and public gives rise to plethora of challenges and barriers related to perception of AI. To add to the challenges list are the barriers associated with incubating and scaling AI initiative in the company as most successful AI projects are required to follow comprehensive lifecycle. Figure 2 shows the AI lifecycle and barriers associated with each stage. Any AI initiative requires problem formulation or use case identification, gathering data, examples or constraints, model training and validation, deployment, and feedback loop. The most common barrier to any AI project is access to high quality data or lack of infrastructure to build scalable data pipelines. Whether we are building a learning system or decision system (optimization), quality of data and examples to learn from has direct impact on the performance of the project (Cortes et al., 1995; Gudivada et al., 2017).

Figure 2. Al lifecycle and associated barriers for each phase

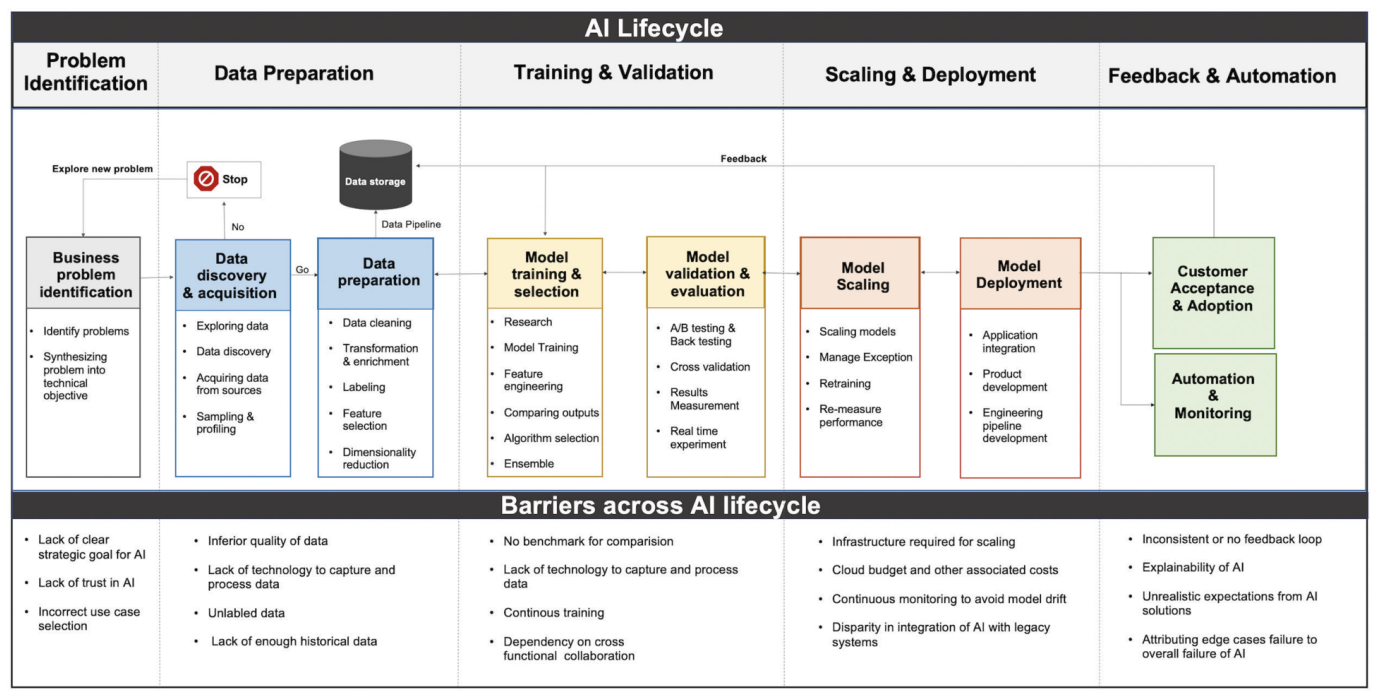

One of the most important assumptions for any (weak) AI system used in industry today is that underlying distribution of its data doesn't change i.e., the system has ability to still generalize when new previously unseen data becomes available. However, in real world, especially in stochastic environments (e.g., ever-changing customer behavior), or when there are shocks to the system, this assumption is usually broken leading to failure of underlying algorithms. This is called as model drift in AI (Gama et al., 2004). It is of paramount importance in AI to continuously monitor for drift which in turn require dedicated commitment and resources (Nelson et al., 2015). If left unchecked, the predictions from AI suffering from drift will lead to erroneous results thereby impacting the adoption of AI across an organization further damaging its perception. This is fundamentally different from way classical enterprise IT projects are set-up where once project is up and running, companies usually move most of the resources to other initiatives as there is no concept of model drift. This is also the reason why AI has been so successful in areas like image or voice recognition as these are less prone to model drift. On the other hand, Supply Chain Management is highly susceptible to model drift, 
not only due to its dependencies on various interlinked chains, but also due to changes in customer preferences as well as supplier/manufacturing environment. Hence, implementing AI across Supply Chain Management requires a highly collaborative and connected environment (Fawcett et al., 2007; Horvath, 2001; Min et al., 2005; Scholten \& Schilder, 2015)

\section{Supply Chain Management: Definition and Al applications}

Supply Chain Management is a discipline that has been thought of as a management philosophy (Hugo, 2018; Mentzer et al., 2007; Werner, 2013) and the set of processes and functions that are needed to successfully implement this philosophy in the real world. The core genesis of supply chain management is that, to serve the customer better and maintain a competitive market position, the various tasks and actions that need to happen to deliver flow of information/goods from supplier to the end customer and vice versa, requires a coordinated and collaborative effort at inter- and intraorganizational levels. It believes that higher degree of alignment among various actors of the supply chain will lead to, either direct or indirect benefits to the bottom line of each actor, thereby increasing the efficiency of the overall supply chain (Ellram, 1991; Min \& Mentzer, 1999; Stock \& Boyer, 2009). A successful SCM demonstrates:

1. Strategic coordination of activities and functions

2. Mutual collaboration of information

3. Shared understanding of risks and rewards

4. Global optimization across a common goal

5. Integrated technology and processes to enable flow of data and information

6. Investing in long term relationships

7. Clear understanding on role of artificial intelligence, and alignment on human-AI interaction

Figure 3 shows a schematic of a supply chain along with key business functions that are part of $\mathrm{SCM}$. For example, Procurement (or purchasing) is about selecting the supplier from candidates list, placing buy orders by negotiating the most optimal price, and maintaining long-term relationship with the supplier (Carr \& Smeltzer, 1999; Monczka et al., 2015). Manufacturing deals with actual production of the goods and building highly effective core processes like order management, productivity of assets, preventive maintenance, labor planning etc. Demand planning and forecasting is a key driver of major activities that happen in the supply chain management: from placing order to the suppliers, estimating the lead time of when the orders will arrive from the supplier to manufacturer warehouse, how much time will it take to manufacture goods, and ultimately providing reliable ETAs on when the goods can leave the manufacturer warehouse to be delivered either to a distribution node or directly to the retailer. Logistics refers to the set of activities within supply chain management that plans and executes the efficient flow of inventory inside and outside of organization to meet the customer requirements (Christopher, 2016). Inventory management is about guaranteeing availability of inventory at a particular step in the supply chain.

\section{Applications of Al in Supply Chain Management}

The rapid advances in Artificial Intelligence have made its strides across several areas of Supply Chain Management. Table 1 shows key areas where successful usage of AI has been reported in the literature. The benefits of deploying AI include productivity improvement in warehouse operations (Karásek, 2013; Seward, 2020), cost minimizations, increase in customer satisfaction by guaranteeing availability, and downtime minimization via predictive maintenance thereby increasing productivity (Bughin et al., 2017; Martin \& Leurent, 2017; Webster \& Ivanov, 2020). Some emerging areas of active research and application include how AI could be used to aid various supply chain activities in disaster management with emphasis on realistic resource planning and deployment when such an event happens (Fiedrich \& Burghardt, 2007; Sun et al., 2020). Take for example climate change, which 
Figure 3. Supply Chain Management- functions, processes, partnerships
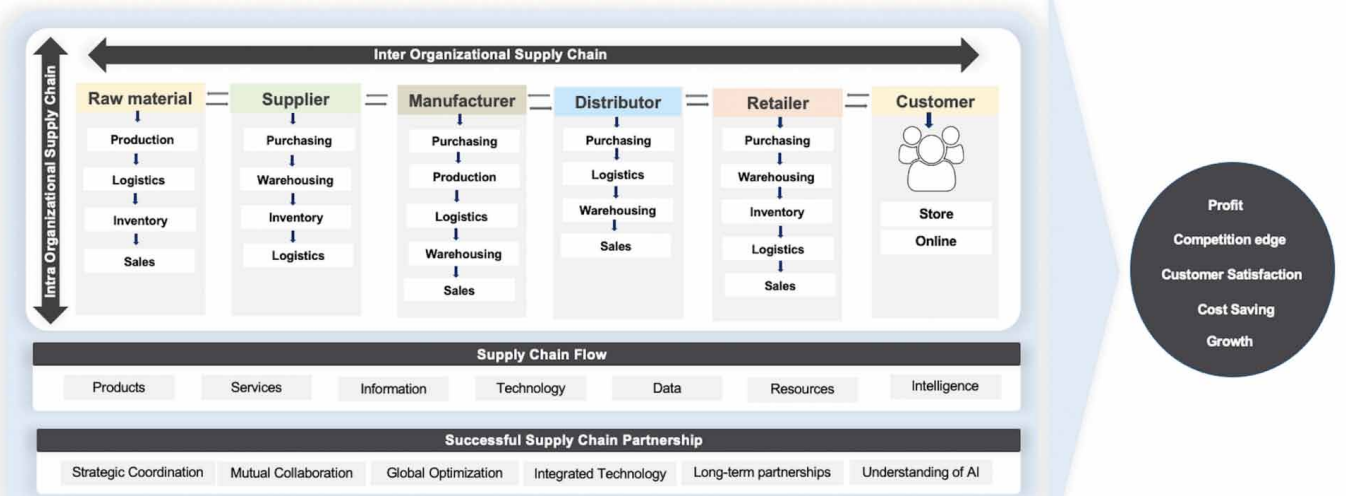

according to Carbon Disclosure Project (CDP) poses $\$ 1.3$ trillion risk to the global supply chain over next five years (Ghadge et al., 2020). Climate change has increasingly made the weather predictions window smaller for when a natural disaster might strike. The increased frequency of erratic weather patterns like prolonged excessive heat waves, flash floods or delay in arrival of season etc., have made supply chains more volatile, risky and is testing its resilience. By integrating climate related AI into supply chain models, organizations can improve their operations and strategic planning thereby minimizing climate related risks (Huntingford et al., 2019, Stein, 2020).

Table 1. Applications of Al across various SCM functions

\begin{tabular}{|c|c|c|}
\hline SCM Functions & Objectives & AI Usage \\
\hline Strategy and Operations Planning & $\begin{array}{l}\text { Strategic alignment across all actors } \\
\text { to gain operational efficiency }\end{array}$ & $\begin{array}{l}\text { - Customer Demand Forecast } \\
\text {. End-to-end optimization }\end{array}$ \\
\hline $\begin{array}{l}\text { Sourcing and } \\
\text { Procurement }\end{array}$ & $\begin{array}{l}\text { Obtaining optimal products from } \\
\text { optimal vendors on optimal terms }\end{array}$ & $\begin{array}{l}\text { - Supplier analytics and selection } \\
\text { - Optimal cost negotiations }\end{array}$ \\
\hline Production & $\begin{array}{l}\text { Optimal allocation of assets to boost } \\
\text { productivity }\end{array}$ & $\begin{array}{l}\cdot \text { Preventive maintenance } \\
\cdot \text { Defect reduction } \\
\cdot \text { Optimal labor allocation }\end{array}$ \\
\hline Logistics and Distribution & $\begin{array}{l}\text { Optimize all efforts to have } \\
\text { continuous flow of goods at lowest } \\
\text { cost from source to customers }\end{array}$ & $\begin{array}{l}\text { - Smart warehousing } \\
\text { - Automated replenishment } \\
\text { - Accurate inventory tracking } \\
\text { - Optimal Network planning }\end{array}$ \\
\hline Marketing and Sales & $\begin{array}{l}\text { Integrate } \mathrm{SC} \text { with customer demand } \\
\text { for increasing profit and market } \\
\text { share }\end{array}$ & $\begin{array}{l}\text { Personalization } \\
\text { - Digital Target Marketing } \\
\text { - Advance market research }\end{array}$ \\
\hline Extreme events readiness & $\begin{array}{l}\text { Identify solution for extreme } \\
\text { changes and events which can } \\
\text { impact overall supply chain }\end{array}$ & $\begin{array}{l}\text {. Climate and weather change } \\
\text { prediction } \\
\cdot \text { Demand volatility in natural disaster } \\
\& \text { unprecedented events (Earthquake, } \\
\text { pandemic) }\end{array}$ \\
\hline
\end{tabular}




\section{Barriers of Implementing Artificial Intelligence in Supply Chain Management}

While Artificial Intelligence has seen accelerated adoption across many industries, there have been increasing amount of academic literature and executive reports where it is yet to completely re-shape the organization (Brock \& Von Wangenheim, 2019; Carter 2018; Ransbotham et al., 2019). While top leadership might be bought into the promise of AI and believe it can give an edge over competition, the middle management is still skeptical about how AI can benefit them (Kolbjørnsrud et al., 2017). The gap between potential and scalable execution/adoption is increasing every single day. In the organizations that have successfully implemented and benefited from AI, have two main ingredients for success: (a) belief in making data driven decisions thereby building strong data culture; and (b) leadership is making consistent effort to invest in AI training and talent across the company. When it comes to Supply Chain Management, the challenges of AI implementation and adoption compound due to need for multi-firm collaboration and need to share information/data across every link in the supply chain. Figure 4 shows the barriers related to AI implementation in SCM categorized into ten different areas, and Table 2 enlists sub-barriers for each highlighting if it affects inter- or intra- SCM organization.

Figure 4. Barriers of $\mathrm{Al}$ implementation in SCM

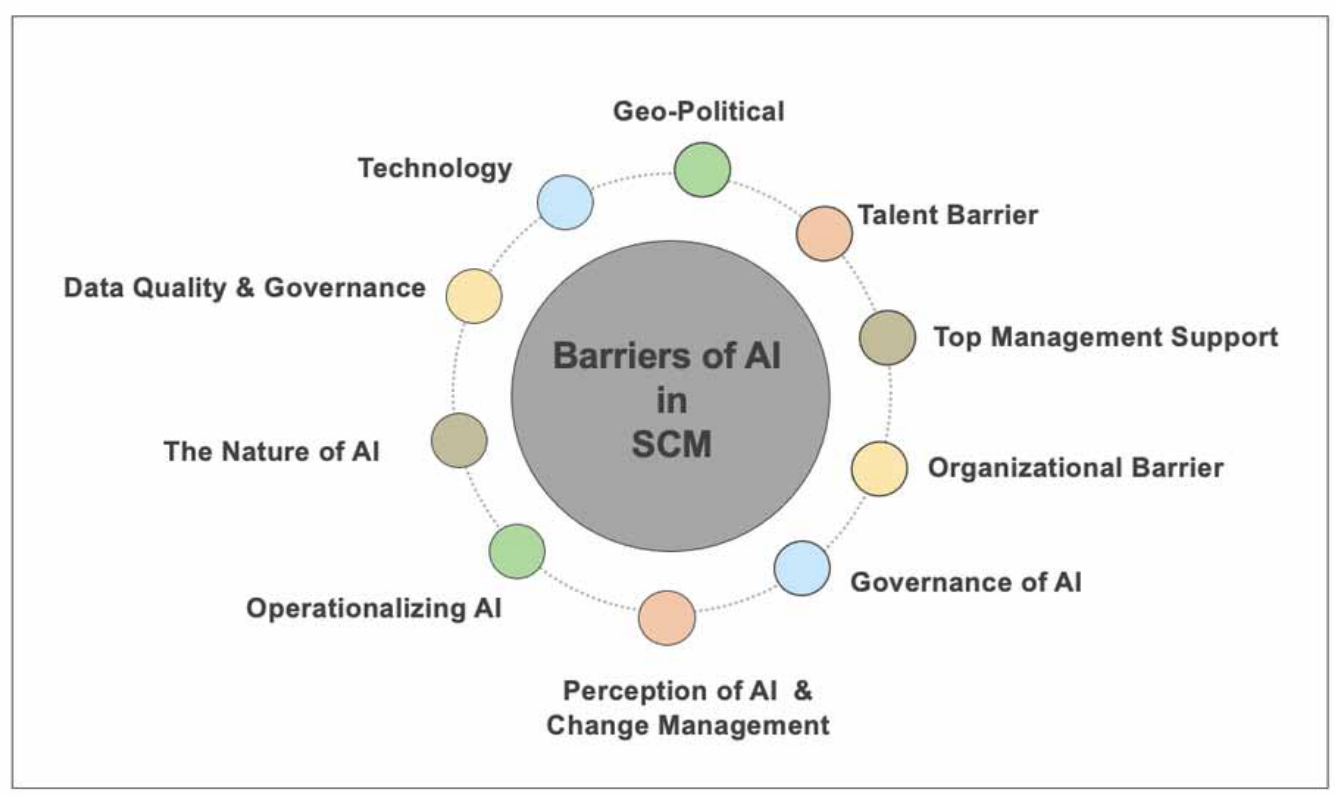

\section{Top Management Support}

The support of top management of the company plays a direct role in all stages of AI - from providing support during incubation / research phase, enabling experiments to get feedback, and eventually approving to scale AI within their organization. In an AI first SCM company, the leadership is more open to take risks, enable more experimentation both at inter and intra-organization level, and provide dedicated resources for AI specific initiatives. These leaders continuously evolve their thinking and are constantly championing AI both in inter-organization executive meetings as well as within their organizations. Their maturity in AI also decides the strategic direction for 'Build vs Make' decision of $\mathrm{AI}$ in their firm. 
Table 2. Barriers related to $\mathrm{Al}$ in SCM

\begin{tabular}{|c|c|c|c|}
\hline Area & Barrier & Intra & Inter \\
\hline \multirow{7}{*}{ Organizational Barrier } & Lack of general understanding of AI & $\mathrm{x}$ & $\mathrm{x}$ \\
\hline & Asymmetry in understanding of AI potential & $\mathrm{x}$ & $\mathrm{x}$ \\
\hline & Lack of clear goals for projects that involve use of AI & $\mathrm{x}$ & $\mathrm{x}$ \\
\hline & Disparity in macro goals \& objectives across actors of SC & $\mathrm{x}$ & $\mathrm{x}$ \\
\hline & Size of various firms/business in the SCM & & $\mathrm{x}$ \\
\hline & Unclear ownership boundaries & $\mathrm{x}$ & $\mathrm{x}$ \\
\hline & Misaligned strategy of various SCM actors (strategic vs tactical) & & $\mathrm{x}$ \\
\hline \multirow{8}{*}{$\begin{array}{l}\text { Top Management } \\
\text { Support }\end{array}$} & Relationships between leaders across various parts of SC & & $\mathrm{x}$ \\
\hline & Communication and Collaboration related to $\mathrm{AI}$ initiatives & $\mathrm{x}$ & $\mathrm{x}$ \\
\hline & Lack of trust in AI & $\mathrm{x}$ & $\mathrm{x}$ \\
\hline & Lack of commitment towards AI & $\mathrm{x}$ & $\mathrm{x}$ \\
\hline & Build vs. Make decision & $\mathrm{x}$ & $\mathrm{x}$ \\
\hline & No commitment towards resource sharing & & $\mathrm{x}$ \\
\hline & Incorrect use case for AI & $\mathrm{x}$ & $\mathrm{x}$ \\
\hline & No alignment on priorities for where and when to use AI & $\mathrm{x}$ & $\mathrm{x}$ \\
\hline \multirow{8}{*}{ The Nature of AI } & Identify right problems for AI & $\mathrm{x}$ & $\mathrm{x}$ \\
\hline & Explainability of AI & $\mathrm{x}$ & $\mathrm{x}$ \\
\hline & Reliance on substantial amounts of data for training & $\mathrm{x}$ & $\mathrm{x}$ \\
\hline & Long and Iterative life cycle & $\mathrm{x}$ & $\mathrm{x}$ \\
\hline & Inconsistent or no feedback loop & $\mathrm{x}$ & $\mathrm{x}$ \\
\hline & Scaling & $\mathrm{x}$ & $\mathrm{x}$ \\
\hline & Horizontal nature of AI & & $\mathrm{x}$ \\
\hline & Need for experimentation & $\mathrm{x}$ & $\mathrm{x}$ \\
\hline \multirow{5}{*}{ Data Quality \& Governance } & Lack of intent to share information & & $\mathrm{x}$ \\
\hline & Inferior quality of data & $\mathrm{x}$ & $\mathrm{x}$ \\
\hline & Lack of technology to capture and process data & $\mathrm{x}$ & $\mathrm{x}$ \\
\hline & No consistent framework to share data across various players & & $\mathrm{x}$ \\
\hline & Confusion around role of classical IT vs. AI teams & $\mathrm{x}$ & $\mathrm{x}$ \\
\hline \multirow{6}{*}{$\begin{array}{l}\text { Perception of AI } \\
\text { \& Change Management }\end{array}$} & Inconsistent performance metrics & $\mathrm{x}$ & $\mathrm{x}$ \\
\hline & Inability to attribute benefits of $\mathrm{AI}$ across all players of SCM & & $\mathrm{x}$ \\
\hline & Lack of patience among leaders and business partners & $\mathrm{x}$ & $\mathrm{x}$ \\
\hline & Unrealistic expectations from AI solutions & $\mathrm{x}$ & $\mathrm{x}$ \\
\hline & Attributing edge cases failure to overall failure of AI & $\mathrm{x}$ & $\mathrm{x}$ \\
\hline & Uncertainty on future with AI systems & $\mathrm{x}$ & $\mathrm{x}$ \\
\hline \multirow{3}{*}{ Operationalizing AI } & Disparity in integration of AI with legacy systems & $\mathrm{x}$ & $\mathrm{x}$ \\
\hline & Inconsistency and incompatibility of various systems across the SCM that consume AI output & & $\mathrm{x}$ \\
\hline & Extreme cross functional collaboration needs & & $\mathrm{x}$ \\
\hline \multirow{3}{*}{ Governance of AI } & Conflict of interest among various actors in SCM & & $\mathrm{x}$ \\
\hline & Accountability of Algorithms & $\mathrm{x}$ & $\mathrm{x}$ \\
\hline & Misalignment on ethical and governance policies for use of AI & & \\
\hline
\end{tabular}


Table 2. Continued

\begin{tabular}{|l|l|l|}
\hline \multirow{5}{*}{ Area } & Barrier & Inter \\
\hline \multirow{3}{*}{ Geo-political } & Scarcity of general AI talent pool & $\mathrm{x}$ \\
\cline { 2 - 3 } & In-consistency in AI talent across various actors & $\mathrm{x}$ \\
\cline { 2 - 4 } & Funding disparity for AI initiatives across organizations of a SC & $\mathrm{x}$ \\
\hline \multirow{2}{*}{ Technology } & Lack of consistent laws around use of AI and collaboration & $\mathrm{x}$ \\
\cline { 2 - 4 } & Government interventions & $\mathrm{x}$ \\
\cline { 2 - 4 } & Lack of dedicated infrastructure for training algorithms & $\mathrm{x}$ \\
\cline { 2 - 4 } & Computational costs increase with scaling & $\mathrm{x}$ \\
\cline { 2 - 4 } & Dedicated computing budget & $\mathrm{x}$ \\
\cline { 2 - 4 } & Integration capabilities with supply chain hardware & $\mathrm{x}$ \\
\hline
\end{tabular}

While the top management support is important, it is also imperative that the leadership across various actors of inter-organization supply chain is aligned and has clear understanding of how AI initiatives will benefit them, either directly or indirectly. Not every leader across various businesses needs to have in-depth understanding of machine learning or optimization, but they do need to share a common belief that leveraging data to make decision is better than gut instinct. Lack of this alignment around use of data and belief in power of AI can pose a major barrier to implementation of AI and create a butterfly effect in journey of an AI initiative. Overall, the top management of each actor of the supply chain needs to be aligned towards a macro benefit from AI, committed to share resources / data / information, agree on potential use-cases where AI can be powerful, and lastly, be a champion of AI within their organization.

\section{The Nature of Al}

Most applications that use Artificial Intelligence in industry either optimize for increase in predictive accuracy, and/or to surface new insights that are not easily detectable by classical business intelligence systems. However, it is well documented that this increase in predictive accuracy (e.g.: Deep Learning framework) comes at cost of increasing model complexity thereby making it extremely challenging for humans to understand why the model worked. This is often referred to as "black-box" nature of Artificial Intelligence. The reason why AI approaches have increased in model complexity is because of availability of large amounts of training data. More the data better are the odds for AI to learn the intricate structures in the data which help in boosting its predictive power (Bengio, 2012; LeCun et al., 2015; LeCun, 2019). Understanding model complexity is an active area of research (called Explainable Artificial Intelligence or XAI) among the scientific community (Doran, 2017; Shin, 2021), but there is no consensus yet on how to decipher the inner workings of complex model frameworks (Bathaee, 2017; Grimsley et al., 2020).

When it comes to Supply Chain Management, the black box nature of AI represents a major hurdle to supply chain as there are humans in the loop for most decision making and planning. Consider for example area of demand planning where AI has tremendous potential and wide adoption. A common survey of available literature will cite that most industry systems use some combination of deep neural networks, xgboost in conjunction with classical time series framework to learn customer demand. However, strategic nature of supply chain implies that this demand needs to be shared across both intra- and inter- departments like finance, labor operations, supplier/manufacturer etc. This demand is then linked to internal planning systems (e.g.: financial planning, labor plans etc.). Across most industries, humans (e.g.: store general manager, finance managers etc.) still hold accountability for the decisions, and it is unfair to expect them to incorporate these "black-box" recommendations into 
their systems even though they are hard to defend or explain. While collaboration is a key pillar for Supply Chain Management, for AI, it warrants that it is also explainable for it to make inroads.

The other major hurdle that AI faces in SCM is lack of understanding of role that feedback loops and experimentation play in increasing model performance. Take for example recommendation systems - one of the most widely used applications of AI in the industry today. Modern day recommender systems rely on vital data stream that feeds back the user activity (e.g.: clicks, likes etc.) to the underlying AI agent thereby enabling them to keep learning the stochastic user behavior. Small feedbacks like quality of ads matching, changes in user clicks, changes in advertiser perception etc. in near real-time provide crucial signal for AI to adapt and respond. While in supply chain, excessive flow of information about stochastic nature of demand can create bullwhip effect (Yang et al., 2021), a constant monitoring of various downstream systems (like increased variability of purchase order) can provide feedback to all AI systems and prevent bullwhip effect from happening.

Lastly, lifecycle of AI projects is longer than conventional software lifecycle. They also differ in fact that they keep evolving based on feedback loop and availability of more data. Unlike Software Development Life Cycle (SDLC), when new scenarios/capabilities are fed into AI models they require re-training and validation. During execution stage, an AI based solution requires constant monitoring for drift, keep validating the relevance of results and capture deviation from objective. However, in SDLC solutions once implemented are maintained for continuous production run. This long and evolving nature of AI initiatives and need for constant monitoring implies commitment from management, as well as dedicated resources on on-going basis. For initiatives that span interorganizational level, there needs to be strategic alignment and commitment to have resources available to prevent any bottlenecks.

\section{Organizational Barrier}

Organizational barriers in related to AI implementation can be classified into six main buckets:

1. sheer size and scale of the company that makes adopting AI challenging,

2. workforce's attitude and resistance to change for AI as it requires re-skilling and learning new ways of working,

3. general understanding of AI itself across the organization,

4. competing priorities across intra-business verticals as well as at inter-organizational level,

5. misaligned goals/OKRs, and,

6. high upfront costs associated with AI initiatives

Businesses in supply chain have conventional organizational structures where AI projects are usually incubated or piloted across vertical functions with a narrow goal or objective function. This problem is exacerbated by fact that each vertical has misaligned goals and OKRs against which they are training AI which leads to problem of confounding variables when analyzing impact of AI thereby creating ROI issues. This variability in goals and priorities, both at inter- and intra- organizational levels, hinders the acceptance of AI proposal and makes collaboration very challenging leading to de-prioritization, delays, and/or eventual abandonment of AI initiative.

High upfront costs associated with AI initiatives might also pose itself as inter-organization barrier as it may not excite all stakeholders of supply chain due to competing priorities and no dedicated budget for AI. The ROI for an AI solution is also challenging and varies based on use case of AI implementation. For strategic AI initiatives like consumer demand forecasting, the AI solutions are expected to realize a long-term business impact in form of accelerated growth, better customer experience or efficient supply chain operations benefits of which are comparatively difficult to estimate at an early stage, as well as asymmetric across various actors of supply chain. High upfront costs, and long-term strategic nature of AI initiatives makes an extremely challenging environment for AI to succeed. 


\section{Data Quality and Governance Barriers}

The reliance of modern-day AI approaches on enormous amounts of training data also poses a hurdle in implementation of AI in Supply Chain Management, especially at inter-organization level. While techniques like multi-task learning and transfer learning (Chen et al., 2019; Li \& Hoiem, 2017; Tan et al., 2018) have been proposed to overcome the issue of large datasets required for training, it is still in early stages to be successfully deployed in real world applications. Quality of the big data also plays a major role in AI adoption as it directly impacts model performance. It has been widely conjectured and proved by experiments that data quality issues like random errors, missing values, inaccurate values, confounding factors in generation of data, duplicate records etc. limit the model accuracy to an upper bound of 75\% (Cortes et al., 1995; Gudivada et al., 2017; McGilvray, 2021).

The need for substantial amounts of superior quality data warrants that all supply chain actors should collaborate to

a. build a unified data platform with consistent data definitions,

b. have clear responsibilities and ownerships to log various types of data generated across various legs of supply chain, and

c. invest and commit to dedicated resources to maintain data quality.

This data transparency should be the first step towards successful implementation of AI across the supply chain, both at inter and intra organization level. Along with data quality, investments in data governance are also needed to ensure data is used safely in accordance with corporate governance rules and government laws.

\section{Technology Barriers}

Developing artificial intelligence algorithms requires building hypothesis on environment where AI agent needs to operate, followed by training the agent under constraints of this environment which usually requires lots of iterations with different structures of algorithms (tree based, shallow neural networks, deep neural nets etc.), trying different architectures, tuning the hyperparameters of the models to boost accuracy, combining different types of learning paradigms (supervised, semi-supervised, unsupervised etc.). All this implies that developing AI solutions require not only a dedicated infrastructure, but also high upfront computing budget. Once the agent has been trained and tested in real world, the algorithm now needs to be scaled which again leads to explosion in computational costs.

Along with above requirements for building AI solutions, supply chain problems require algorithms to ingest different types of IoT data originating from plethora of sensors embedded in various parts of supply chain (e.g.: temperature sensors on the container, tracking devices etc.). This imposes additional technology constraints on need for system compatibility to share and ingest different types of data.

\section{Perception of $\mathrm{Al}$ and Change Management Barriers}

One of the key roadblocks for AI in supply chain management is inconsistency and misalignment in performance metrics for AI. Two business verticals within same organization can interpret the performance of an algorithm differently, partly due to (a) sub-conscious bias stemming from uncertain future if the AI system is implemented, and/or (b) narrow scope of the AI initiative which usually misses out how to handle edge cases/exceptions that are of plenty across the supply chain. Instead of embracing AI that it was able to come closer to (or match) human performance, the unrealistic expectations from AI (of achieving superhuman performance) makes it a no-go in workforce's mind. This creates a negative feedback loop for AI. By its very nature, AI agent learns from data, examples or feedback, and hence poor performance or a missed situation by $\mathrm{AI}$ is an opportunity to 
give the agent much needed feedback for it to improve. Lack of patience, uncertainty of the future with AI, low initial performance, misinterpretation of metrics etc. all add up to a major inevitable resistance that warrants an effective change management strategy and top's down approach towards AI implementation and adoption.

Across inter-organization, perception of how AI can manifest itself in form of lack of collaboration around data sharing or general collaboration which is a bedrock of supply chain management. Lack of communication around AI initiatives across supply chain players can lead to competitive dynamics in once collaborative environment.

\section{Barriers During Operationalizing AI}

The disparity in the information technology (IT) systems that are eventually going to consume algorithm's output creates integration challenges for AI implementation at inter-organizational level. This disparity stems from fact that not every player in the supply chain is equally progressed in their digital transformation journey, and even if they were, lack of consistency on technology norms creates misalignment between IT systems making it challenging to algorithmically share intelligence and information.

Most of the AI approaches require inhouse integration with data platforms and require a training platform to train and produce the output to be consumed by a downstream execution system. However, most players in supply chain either employ legacy IT systems or use third party software (SaaS) for the same, thereby making integration challenging as it requires building a consumption layer in between for output to be seamlessly integrated. This requires dedicated engineering resources and partnership between science team as well as business function engineering teams.

\section{Governance of Al}

Since most of the advances in modern day AI happened over a very short timeframe and led by handful of corporations (like Google, Apple etc.), the development of governing standards around how, when and under what circumstances to use AI have been left behind. Infact, there is no agreed upon consensus or a central administrative body on a governance framework around usage of AI like we have in other areas of real-world operations (e.g.: standard operating procedures for labor, Federal Aviation Administration, Center for Disease Control etc.). This manifests itself in form of a barrier for AI implementation, especially across inter-organization supply chain. In absence of clear legal rules and regulation for AI, Supply Chain partners must continuously go through alignment across three broad areas -

a. Accountability of algorithms implies that there is common understanding of what problems are being solved using AI, clarity on ownership and accountability in event AI system fails or goes down, transparency on risks and benefits of deploying AI system, and that algorithms are doing their job responsibly.

b. Ethical concerns on usage of AI deals with agreed upon principles and criteria under which AI will and can be used across the supply chain. Consider the following example: one of the actors in the supply chain employs personalized pricing strategies for its end consumer. To do so, it uses an AI agent that recommends higher prices for certain consumers which in turn can be attributed to their gender, age, race, income levels etc. Which this might be profitable strategy and based on solid scientific basis (e.g.: price elasticity), it might be unfair from human rights point of view and not in-line with corporate governance and values of other actors in the supply chain. This creates friction between the leadership as well as conflict of interest.

c. Data related issues like data security and sharing permissions. 
The willingness to come to the table to self-govern and use AI responsibly creates a resistance among organizations to partner and invest in AI solution for various supply chain function even when they believe in the promise of AI.

\section{Talent Barriers}

Access to AI talent pool is a consistent barrier across any industry or sector including supply chain management. Numerous industry wide surveys (O'Reilly, 2021, KPMG, 2021) have found that lack of skilled AI workers and difficulty in hiring as one the top reasons for AI adoption within their organization. While universities have ramped up their offerings to train future graduates in the field of AI, there is still significant gap of experienced professionals in this field. Most real-world AI initiatives require decent understanding of the business domain for scientists to effectively understand and build the model that scales. Most university graduates often lack this experience. This supplydemand imbalance creates so called "data scientists" in high demand thereby increasing cost for the company. Organizations need to create separate job families for AI with higher compensation structure in order to effectively compete for the AI talent.

\section{Geopolitical Barriers}

Geopolitical risks are usually catastrophic for SCM in general, and they also can adversely impact the performance of AI systems in the supply chain. Geopolitical tensions add noise to the underlying data which may not only change the distribution of data used for training the AI, but also adds a period of uncertainty for the future as to when will things return to normal. For example, consider increase in global oil prices due to tension in middle east, or increase in tariffs due to trade-negotiations between major countries etc. Both these situations offer increased period of uncertainty and usually add lagged noise to the data. While AI can help companies navigate through these situations by building simulations and offering optimal solutions, it can also get adversely impacted if models are not re-trained properly or if such geopolitical decisions are not labelled properly in the datasets.

\section{Overcoming AI Barriers of Supply Chain - A Coordinated Approach}

The compounding barriers obstructing the full potential of AI in Supply Chain Management not only requires significant changes within the organizations but also across the overall AI ecosystem within which supply chain exists. Policy makers, researchers, industry practitioners and governments (see figure 5) need to come together to build a conducive environment for AI to thrive.

For example, industry practitioners of supply chain can take the lead by putting in effort to understand fundamentals of AI, identify the right problems where AI has higher odds of succeeding in their specific area, build the right strategy for AI to go from incubation to running operations etc. Industry leaders can promote data driven culture at intra organization level as well as with external partners and can advocate for far-reaching consequences of machine-based decision and evaluate the impact of AI solutions implemented across supply chain to further promote benefits of AI adoptions. They can enable organizational changes and increase readiness to embrace AI among various players of supply chain by putting principles to practice and building partnerships based on trust and mutual gains.

Researchers can extend recent advances in AI to areas like designing algorithms that don't need large data sets or that use less compute power at time of scaling. To tackle the issue of variability and connectedness in supply chain, researchers can focus on paradigms like transfer learning or multi-task learning to ensure learnings from one part of supply chain can influence/leveraged by other parts of supply chain. They can partner with industry professionals on demonstrating feasibility of current AI technology in real-world situation, which in turn, would boost confidence and adoption.

Lawmakers and politician can play a massive role in creating a conducive broader ecosystem of AI in the country. For example, in their 2017 development plan, China laid out its vision to be AI superpower by 2030. With a coordinate effort around policy support and investments, the adoption 


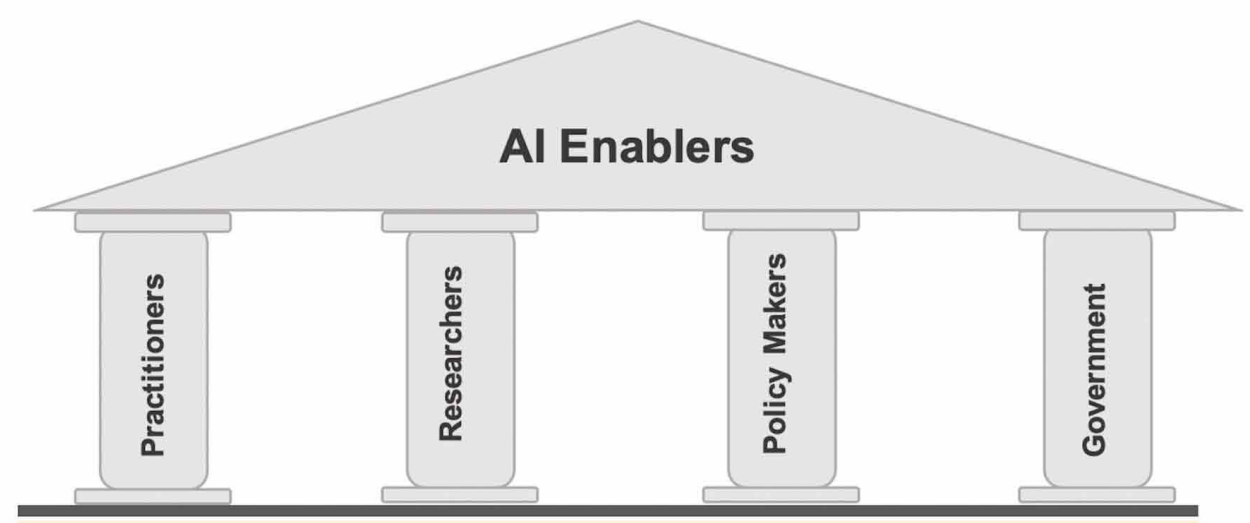

\begin{tabular}{|c|c|c|c|}
\hline \multicolumn{4}{|c|}{ What actions these agents should take? } \\
\hline $\begin{array}{l}\text { - Acquire knowledge } \\
\text { of fundamentals of } \\
\text { Al } \\
\text { - Connect the dots } \\
\text { between business } \\
\text { domain and } \\
\text { Al to identify } \\
\text { right problems that } \\
\text { Al can tackle } \\
\text { Allocate optimal } \\
\text { resources and } \\
\text { funds for Al } \\
\text { initiatives }\end{array}$ & $\begin{array}{l}\text { Al research relevant to } \\
\text { SCM: } \\
\text { - } \quad \text { Explainable AI } \\
\text { - } \text { Algorithms with } \\
\text { lesser dependency } \\
\text { on labelled data } \\
\text { - Integration of Al } \\
\text { with next gen } \\
\text { technologies (loT) } \\
\text { - Paradigms that } \\
\text { allow for horizontal } \\
\text { learning (transfer, } \\
\text { multi-task } \\
\text { learning etc.) }\end{array}$ & $\begin{array}{l}\text { Educate } \\
\text { themselves on } \\
\text { potential benefits } \\
\text { and risks } \\
\text { associated with } \\
\text { Al to the society } \\
\text { and humanity } \\
\text { Create sense of } \\
\text { urgency among } \\
\text { experts to } \\
\text { formulate code of } \\
\text { conduct for more } \\
\text { responsible Al }\end{array}$ & $\begin{array}{l}\text { - Promote public- } \\
\text { private } \\
\text { partnerships to } \\
\text { influence constituti } \\
\text { onal rights for Al } \\
\text { creation \& usage }\end{array}$ \\
\hline \multicolumn{4}{|c|}{ What will these agents enable? } \\
\hline $\begin{array}{l}\text { - } \begin{array}{l}\text { Data driven } \\
\text { decision }\end{array} \\
\text { - Organizational \& } \\
\text { cultural shift } \\
\text { needed for Al } \\
\text { - Increased } \\
\text { readiness to } \\
\text { embrace Al }\end{array}$ & $\begin{array}{l}\text { Strong partnership } \\
\text { with practitioners } \\
\text { to demonstrate } \\
\text { feasibility of Al to } \\
\text { solve harder } \\
\text { problems } \\
\text { Evolved algorithms } \\
\text { catering real world } \\
\text { complexities }\end{array}$ & $\begin{array}{l}\text { Clear governance } \\
\text { framework around } \\
\text { ethics and } \\
\text { societal issues } \\
\text { related to Al } \\
\text { - Improved } \\
\text { awareness to } \\
\text { increased } \\
\text { adoption of } \mathrm{Al}\end{array}$ & $\begin{array}{l}\text { Better laws/acts } \\
\text { (like GDPR) } \\
\text { that provide clear } \\
\text { government } \\
\text { standing on key } \\
\text { issues around Al } \\
\text { - } \begin{array}{l}\text { Regulation around } \\
\text { cross-cultural Al } \\
\text { partnerships }\end{array}\end{array}$ \\
\hline
\end{tabular}

of AI across all industries, including supply chain has doubled in 2019. It has done so by creating an ecosystem (e.g: accommodative labor laws that displaced labor because of use of AI) for companies across several industries to adopt AI (Burnson, 2021; Candelon et al., 2021).

Government can also help spur wave of innovation by funding research universities as well as creating development programs that help is re-skilling its workforce in the wave of AI. In the age of globalization where supply chains are highly internationalized and connected, governments can collaborate to create friendly policies that allow for sharing of data and/or resources, as all countries will be beneficiary of an efficient global supply chain. At minimum, governments should make their position clear on where they stand on key issues related to AI adoption and innovation. 


\section{CONCLUSION}

This paper offers a structured review of barriers that impede the adoption of AI across the supply chain. It reinforces the idea that for supply chain management to be cognitively enabled, it needs top managements support, build long term partnerships at inter-organization level, commit dedicated resources to build AI infrastructure, and most importantly have open doors around collaboration of intelligence and data sharing. Ever since the term supply chain management was coined, companies have embraced this philosophy, agreed upon guiding principles with its supply chain partners, and built processes and functions that paved the way highly accelerated growth in economy over last few decades. None of the barriers listed in the paper are insurmountable. If there is a coordinated effort between supply chain industry practitioners, researchers, policy makers and governments, supply chains of the future can become AI first thereby ushering new wave of growth for the economy, and most importantly, serving the customer in most cost-effective way possible when they want it and where they want it. 


\section{REFERENCES}

Agrawal, P., \& Narain, R. (2018, December). Digital supply chain management: An Overview. IOP Conference Series. Materials Science and Engineering, 455(1), 012074. doi:10.1088/1757-899X/455/1/012074

Al-Turjman, F. (Ed.). (2019). Artificial intelligence in IoT. Springer. doi:10.1007/978-3-030-04110-6

Amershi, S., Weld, D., Vorvoreanu, M., Fourney, A., Nushi, B., Collisson, P., \& Horvitz, E. et al. (2019, May). Guidelines for human-AI interaction. In Proceedings of the 2019 chi conference on human factors in computing systems (pp. 1-13). ACM.

Bathaee, Y. (2017). The artificial intelligence black box and the failure of intent and causation. Harv. JL \& Tech., 31, 889 .

Bengio, Y. (2012, June). Deep learning of representations for unsupervised and transfer learning. In Proceedings of ICML workshop on unsupervised and transfer learning (pp. 17-36). JMLR Workshop and Conference Proceedings.

Bernhardt, C. (2019). Quantum computing for everyone. MIT Press. doi:10.7551/mitpress/11860.001.0001

Bertsimas, D., \& Thiele, A. (2004, June). A robust optimization approach to supply chain management. In International conference on integer programming and combinatorial optimization (pp. 86-100). Springer. doi:10.1007/978-3-540-25960-2_7

Boyd, S., Boyd, S. P., \& Vandenberghe, L. (2004). Convex optimization. Cambridge University Press. doi:10.1017/ CBO9780511804441

Bringsjord, S., Govindarajulu, N. S., Banerjee, S., \& Hummel, J. (2017, November). Do Machine-Learning Machines Learn? In 3rd Conference on" Philosophy and Theory of Artificial Intelligence (pp. 136-157). Springer.

Brock, J. K. U., \& Von Wangenheim, F. (2019). Demystifying AI: What digital transformation leaders can teach you about realistic artificial intelligence. California Management Review, 61(4), 110-134. doi: $10.1177 / 1536504219865226$

Brunson, P. (2021). Global Supply Chain Challenge: China Leverages its Advantage in Artificial Intelligence. Supply Chain Management Review.

Bughin, J., Hazan, E., Ramaswamy, S., Chui, M., Allas, T., Dahlstrom, P., ... Trench, M. (2017). Artificial intelligence: The next digital frontier? Academic Press.

Candelon, F., Jacobides, M., Brusoni, S., \& Gombeaud, M. (2021). China's business 'ecosystems' are helping it win the global A.I. race. Fortune.

Carr, A. S., \& Smeltzer, L. R. (1999). The relationship of strategic purchasing to supply chain management. European Journal of Purchasing \& Supply Management, 5(1), 43-51. doi:10.1016/S0969-7012(98)00022-7

Carter, D. (2018). How real is the impact of artificial intelligence? The business information survey 2018. Business Information Review, 35(3), 99-115. doi:10.1177/0266382118790150

Chen, X., Wang, S., Fu, B., Long, M., \& Wang, J. (2019). Catastrophic forgetting meets negative transfer: Batch spectral shrinkage for safe transfer learning. Academic Press.

Christopher, M. (2016). Logistics \& supply chain management. Pearson UK.

Chui, M., \& Malhotra, S. (2018). AI adoption advances, but foundational barriers remain. McKinsey.

Cortes, C., Jackel, L. D., \& Chiang, W. P. (1995, August). Limits on learning machine accuracy imposed by data quality. KDD: Proceedings / International Conference on Knowledge Discovery \& Data Mining. International Conference on Knowledge Discovery \& Data Mining, 95, 57-62.

Cubric, M. (2020). Drivers, barriers and social considerations for AI adoption in business and management: A tertiary study. Technology in Society, 62, 101257. doi:10.1016/j.techsoc.2020.101257

Dash, R., McMurtrey, M., Rebman, C., \& Kar, U. K. (2019). Application of artificial intelligence in automation of supply chain management. Journal of Strategic Innovation and Sustainability, 14(3), 43-53. 
Doran, D., Schulz, S., \& Besold, T. R. (2017). What does explainable AI really mean? A new conceptualization of perspectives. arXiv preprint arXiv:1710.00794

Dwivedi, Y. K., Hughes, L., Ismagilova, E., Aarts, G., Coombs, C., Crick, T., \& Williams, M. D. et al. (2019). Artificial Intelligence (AI): Multidisciplinary perspectives on emerging challenges, opportunities, and agenda for research, practice and policy. International Journal of Information Management, 101994.

Ellram, L. M. (1991). Supply-chain management: The industrial organisation perspective. International Journal of Physical Distribution \& Logistics Management, 21(1), 13-22. doi:10.1108/09600039110137082

Evtodieva, T. E., Chernova, D. V., Ivanova, N. V., \& Wirth, J. (2020). The internet of things: possibilities of application in intelligent supply chain management. Digital transformation of the economy: Challenges, trends and new opportunities, 395-403.

Fawcett, S. E., Magnan, G. M., \& McCarter, M. W. (2008). Benefits, barriers, and bridges to effective supply chain management. Supply Chain Management, 13(1), 35-48. doi:10.1108/13598540810850300

Fawcett, S. E., Osterhaus, P., Magnan, G. M., Brau, J. C., \& McCarter, M. W. (2007). Information sharing and supply chain performance: The role of connectivity and willingness. Supply Chain Management, 12(5), 358-368. doi:10.1108/13598540710776935

Fiedrich, F., \& Burghardt, P. (2007). Agent-based systems for disaster management. Communications of the ACM, 5O(3), 41-42. doi: $10.1145 / 1226736.1226763$

Gama, J., Medas, P., Castillo, G., \& Rodrigues, P. (2004, September). Learning with drift detection. In Brazilian symposium on artificial intelligence (pp. 286-295). Springer.

Geunes, J., \& Pardalos, P. M. (2003). Network optimization in supply chain management and financial engineering: An annotated bibliography. Networks: An International Journal, 42(2), 66-84. doi:10.1002/net.10082

Ghadge, A., Wurtmann, H., \& Seuring, S. (2020). Managing climate change risks in global supply chains: A review and research agenda. International Journal of Production Research, 58(1), 44-64. doi:10.1080/00207 543.2019.1629670

Goertzel, B. (2007). Artificial general intelligence (C. Pennachin, Ed., Vol. 2). Springer. doi:10.1007/978-3540-68677-4

Goodfellow, I., Bengio, Y., \& Courville, A. (2016). Deep learning. MIT Press.

Grimsley, C., Mayfield, E., \& Bursten, J. (2020). Why attention is not explanation: Surgical intervention and causal reasoning about neural models. Academic Press.

Gudivada, V., Apon, A., \& Ding, J. (2017). Data quality considerations for big data and machine learning: Going beyond data cleaning and transformations. International Journal on Advances in Software, 10(1), 1-20.

Helo, P., \& Hao, Y. (2021). Artificial intelligence in operations management and supply chain management: An exploratory case study. Production Planning and Control, 1-18. doi:10.1080/09537287.2021.1882690

Horvath, L. (2001). Collaboration: The key to value creation in supply chain management. Supply Chain Management, 6(5), 205-207. doi:10.1108/EUM0000000006039

Hugos, M. H. (2018). Essentials of supply chain management. John Wiley \& Sons. doi:10.1002/9781119464495

Huntingford, C., Jeffers, E. S., Bonsall, M. B., Christensen, H. M., Lees, T., \& Yang, H. (2019). Machine learning and artificial intelligence to aid climate change research and preparedness. Environmental Research Letters, 14(12), 124007. doi:10.1088/1748-9326/ab4e55

Jordan, M. I., \& Mitchell, T. M. (2015). Machine learning: Trends, perspectives, and prospects. Science, 349(6245), 255-260. doi:10.1126/science.aaa8415 PMID:26185243

Karásek, J. (2013). An overview of warehouse optimization. International Journal of Advances in Telecommunications, Electrotechnics, Signals and Systems, 2(3), 111-117.

Kolbjørnsrud, V., Amico, R., \& Thomas, R. J. (2017). Partnering with AI: How organizations can win over skeptical managers. Strategy and Leadership, 45(1), 37-43. doi:10.1108/SL-12-2016-0085 
Krizhevsky, A., Sutskever, I., \& Hinton, G. E. (2012). Imagenet classification with deep convolutional neural networks. Advances in Neural Information Processing Systems, 25, 1097-1105.

LeCun, Y. (2019, February). 1.1 deep learning hardware: past, present, and future. In 2019 IEEE International Solid-State Circuits Conference-(ISSCC) (pp. 12-19). IEEE. doi:10.1109/ISSCC.2019.8662396

LeCun, Y., Bengio, Y., \& Hinton, G. (2015). Deep learning. Nature, 521(7553), 436-444.

Li, Z., \& Hoiem, D. (2017). Learning without forgetting. IEEE Transactions on Pattern Analysis and Machine Intelligence, 40(12), 2935-2947. doi:10.1109/TPAMI.2017.2773081 PMID:29990101

Martin, C., \& Leurent, H. (2017). Technology and innovation for the future of production: Accelerating value creation. World Economic Forum.

McGilvray, D. (2021). Executing data quality projects: Ten steps to quality data and trusted information. Academic Press.

Mehrotra, P. (2021). Applications of Artificial Intelligence in the Realm of Business Intelligence. In Research Anthology on Artificial Intelligence Applications in Security (pp. 358-386). IGI Global. doi:10.4018/978-17998-7705-9.ch018

Mentzer, J. T., DeWitt, W., Keebler, J. S., Min, S., Nix, N. W., Smith, C. D., \& Zacharia, Z. G. (2001). Defining supply chain management. Journal of Business Logistics, 22(2), 1-25. doi:10.1002/j.2158-1592.2001.tb00001.x

Michard, F., \& Teboul, J. L. (2019). Predictive analytics: Beyond the buzz. Academic Press.

Min, H. (2010). Artificial intelligence in supply chain management: Theory and applications. International Journal of Logistics: Research and Applications, 13(1), 13-39. doi:10.1080/13675560902736537

Min, S., \& Mentzer, J. T. (1999). Defining supply chain management within marketing strategy. In American Marketing Association. Conference Proceedings (Vol. 10, p. 26). American Marketing Association.

Min, S., Roath, A. S., Daugherty, P. J., Genchev, S. E., Chen, H., Arndt, A. D., \& Richey, R. G. (2005). Supply chain collaboration: What's happening? International Journal of Logistics Management, 16(2), $237-256$. doi:10.1108/09574090510634539

Monczka, R. M., Handfield, R. B., Giunipero, L. C., \& Patterson, J. L. (2015). Purchasing and supply chain management. Cengage Learning.

Moore, A. (2018). A vision for software development. Academic Press.

Nasiri, M., Ukko, J., Saunila, M., \& Rantala, T. (2020). Managing the digital supply chain: The role of smart technologies. Technovation, 96, 102121. doi:10.1016/j.technovation.2020.102121

Nelson, K., Corbin, G., Anania, M., Kovacs, M., Tobias, J., \& Blowers, M. (2015, May). Evaluating model drift in machine learning algorithms. In 2015 IEEE Symposium on Computational Intelligence for Security and Defense Applications (CISDA) (pp. 1-8). IEEE. doi:10.1109/CISDA.2015.7208643

Ransbotham, S., Kiron, D., Gerbert, P., \& Reeves, M. (2017). Reshaping business with artificial intelligence: Closing the gap between ambition and action. MIT Sloan Management Review, 59(1).

Rawat, W., \& Wang, Z. (2017). Deep convolutional neural networks for image classification: A comprehensive review. Neural Computation, 29(9), 2352-2449. doi:10.1162/neco_a_00990 PMID:28599112

Russell, S., \& Norvig, P. (2002). Artificial intelligence: a modern approach. Academic Press.

Scholten, K., \& Schilder, S. (2015). The role of collaboration in supply chain resilience. Supply Chain Management, 20(4), 471-484. doi:10.1108/SCM-11-2014-0386

Seward, C. (2020). Optimizing warehouse operations with machine learning on GPUs. Academic Press.

Shin, D. (2021). The effects of explainability and causability on perception, trust, and acceptance: Implications for explainable AI. International Journal of Human-Computer Studies, 146, 102551. doi:10.1016/j.ijhcs.2020.102551

Singh, N. (2003). Emerging technologies to support supply chain management. Communications of the ACM, 46(9), 243-247. doi:10.1145/903893.903943 
Singh, S., Sharma, P. K., Yoon, B., Shojafar, M., Cho, G. H., \& Ra, I. H. (2020). Convergence of blockchain and artificial intelligence in IoT network for the sustainable smart city. Sustainable Cities and Society, 63, 102364. doi:10.1016/j.scs.2020.102364

Stein, A. L. (2020). Artificial Intelligence and Climate Change. Yale Journal on Regulation, $37,890$.

Stock, J. R., \& Boyer, S. L. (2009). Developing a consensus definition of supply chain management: A qualitative study. International Journal of Physical Distribution \& Logistics Management, 39(8), 690-711. doi:10.1108/09600030910996323

Sun, W., Bocchini, P., \& Davison, B. D. (2020). Applications of artificial intelligence for disaster management. Natural Hazards, 103(3), 1-59. doi:10.1007/s11069-020-04124-3

Szegedy, C., Vanhoucke, V., Ioffe, S., Shlens, J., \& Wojna, Z. (2016). Rethinking the inception architecture for computer vision. In Proceedings of the IEEE conference on computer vision and pattern recognition (pp. 2818-2826). IEEE. doi:10.1109/CVPR.2016.308

Tan, C., Sun, F., Kong, T., Zhang, W., Yang, C., \& Liu, C. (2018, October). A survey on deep transfer learning. In International conference on artificial neural networks (pp. 270-279). Springer.

Toorajipour, R., Sohrabpour, V., Nazarpour, A., Oghazi, P., \& Fischl, M. (2021). Artificial intelligence in supply chain management: A systematic literature review. Journal of Business Research, 122, 502-517. doi:10.1016/j. jbusres.2020.09.009

Webster, C., \& Ivanov, S. (2020). Robotics, artificial intelligence, and the evolving nature of work. In Digital transformation in business and society (pp. 127-143). Palgrave Macmillan. doi:10.1007/978-3-030-08277-2_8

Werner, H. (2013). Supply chain management. Springer.

Yang, Y., Lin, J., Liu, G., \& Zhou, L. (2021). The behavioural causes of bullwhip effect in supply chains: A systematic literature review. International Journal of Production Economics, 236, 108120. doi:10.1016/j. ijpe.2021.108120

Zhu, X., \& Goldberg, A. B. (2009). Introduction to semi-supervised learning. Synthesis Lectures on Artificial Intelligence and Machine Learning, 3(1), 1-130.

Monika Shrivastav is Principal AI Strategy and Operations lead for US Merchandizing and Supply Chain Operations at Walmart Labs. In her current role, she oversees the execution of all advance analytics across Walmart US. Prior to Walmart, she worked in a Fintech startup, Henry Labs, designing features for IOS applications. Prior to that Monika was part of Nomura Investment bank and worked on several projects of Trade Lifecycle Management in Global Market Business Services domain. In her academics, she has done master's in Engineering Management from International Technological University, CA, USA and dual Master of Business Administration in Finance and Marketing from Prestige Institute of Management and Research, Indore, India. She is recipient of the Edelman Laureate medal-2020 from INFORMS. 